\title{
Controlling the Gain of Rod-Mediated Signals in the Mammalian Retina
}

\author{
Felice A. Dunn, ${ }^{1}$ Thuy Doan, ${ }^{1}$ Alapakkam P. Sampath, ${ }^{3}$ and Fred Rieke ${ }^{2,3}$ \\ ${ }^{1}$ Program in Neurobiology and Behavior, ${ }^{2}$ Howard Hughes Medical Institute, and ${ }^{3}$ Department of Physiology and Biophysics, University of Washington, \\ Seattle, Washington 98195
}

\begin{abstract}
Effective sensory processing requires matching the gain of neural responses to the range of signals encountered. For rod vision, gain controls operate at light levels at which photons arrive rarely at individual rods, light levels too low to cause adaptation in rod phototransduction. Under these conditions, adaptation within a conserved pathway in mammalian retina maintains sensitivity as light levels change. To relate retinal signals to behavioral work on detection at low light levels, we measured how background light affects the gain and noise of primate ganglion cells. To determine where and how gain is controlled, we tracked rod-mediated signals across the mouse retina. These experiments led to three main conclusions: (1) the primary site of adaptation at low light levels is the synapse between rod bipolar and AII amacrine cells; (2) cellular noise after the gain control is nearly independent of background intensity; and (3) at low backgrounds, noise in the circuitry, rather than rod noise or fluctuations in arriving photons, limits ganglion cell sensitivity. This work provides physiological insights into the rich history of experiments characterizing how rod vision avoids saturation as light levels increase.
\end{abstract}

Key words: adaptation; retina; rod; noise; rod vision; gain control

\section{Introduction}

Vision operates over an enormous range of light levels, from starlight to noonday sunlight. Thus, the retina uses a limited range of cellular responses to represent environments that differ by $\sim 10^{12}$ in mean light intensity (for review, see Shapley and Enroth-Cugell, 1984). This challenge is not unique to vision, e.g., the auditory system also operates over a range of $\sim 10^{12}$ in sound pressure level (Viemeister and Bacon, 1988). Here we investigate how receptor and network gain controls maintain the sensitivity of rod vision as mean light levels change.

Controlling the gain of rod-mediated signals in the retina exemplifies a general issue: where should gain be controlled within a neural circuit to preserve sensitivity most effectively? The retina provides multiple opportunities for gain control, from the transduction process in the photoreceptors to sites throughout the retinal network. Several issues determine the effectiveness of each site in maintaining sensitivity when light levels change. Early sites, e.g., in the rods, require controlling gain with a signal generated from a few rods, presenting the risk that fluctuations in the

Received Dec. 2, 2005; revised Feb. 27, 2006; accepted Feb. 28, 2006.

This work was supported by National Institutes of Health Grants EY-11850 (F.R.) and T32 EY-07031 (T.D.), National Research Service Award EY-14784 (A.P.S.), a Poncin scholarship (T.D.), Achievement Rewards for College Scientists Foundation (F.A.D.), and the Howard Hughes Medical Institute (F.A.D., F.R.). F.A.D. and F.R. conceived and designed the experiments; F.A.D., T.D., A.P.S., and F.R. performed the experiments; F.A.D. analyzed the data; and F.A.D. and F.R. wrote the paper. We thank Paul Newman for excellent technical assistance, David Paul for providing connexin $36^{-/-}$mice, Orin Packer and Dennis Dacey for providing primate retina, and Kristian Donner, Gabe Murphy, Fred Soo, Barry Wark, and the anonymous reviewers for comments on this manuscript.

Correspondence should be addressed to Fred Rieke, Department of Physiology and Biophysics, HSB Room G424, University of Washington, Seattle, WA 98195. E-mail: rieke@u.washington.edu.

A. P. Sampath's present address: Zilkha Neurogenetic Institute, Department of Physiology and Biophysics, University of Southern California, Keck School of Medicine, Los Angeles, CA 90089

D0I:10.1523/JNEUROSCI.5148-05.2006

Copyright $\odot 2006$ Society for Neuroscience $\quad$ 0270-6474/06/263959-12\$15.00/0 rod signals will produce fluctuations in gain (Rushton, 1965). Late gain controls, e.g., in the ganglion cells, could fail to prevent saturation of intermediate signals within the retina. Finally, gain controls located before or after key sources of noise within the circuitry will have different influences on sensitivity (Graham and Hood, 1992). Adapting circuits throughout the nervous system face some or all of these issues. Studies of rod-mediated signaling in the retina provide an excellent opportunity to understand these general issues because the circuitry is well defined and the relationship to behavior is clear.

At low light levels, rod-mediated signals traverse the mammalian retina through a specialized pathway: $\operatorname{rod} \rightarrow \operatorname{rod}$ bipolar $\rightarrow$ AII amacrine $\rightarrow$ cone bipolar $\rightarrow$ ganglion cell (see Fig. 1) (Dacheux and Raviola, 1986; Sterling et al., 1988; Deans et al., 2002; Volgyi et al., 2004). Amplification in the rod photoreceptors (Baylor et al., 1979b, 1984) and convergence within the rod bipolar pathway (Sterling et al., 1988) allow retinal ganglion cells to respond when a tiny fraction of the rods absorb photons, e.g., a cat ganglion cell can produce several extra spikes when one of the thousands of rods within its receptive field absorbs a photon (Barlow et al., 1971; Mastronarde, 1983a,b). If maintained as light levels increase, this amplification would cause a ganglion cell to reach its maximum firing rate of $\sim 300 \mathrm{~Hz}$ (O'Brien et al., 2002) when $<1 \%$ of the rods absorb photons during the $\sim 200 \mathrm{~ms}$ integration time of rod signals.

Past work has established that the saturation threatened by convergence and amplification is prevented by gain control mechanisms operating within the inner retina, i.e., by interactions between bipolar, amacrine, and ganglion cells (Dowling, 1967; Barlow and Levick, 1969; Enroth-Cugell and Shapley, 1973; Frishman and Sieving, 1995; Naarendorp et al., 2001). However, 
it is not known how or where in the inner retina gain is controlled.

\section{Materials and Methods}

We recorded from mouse (C57BL/6) and primate (Macaca fascicularis, Macaca nemestrina, and Papio anubis) retinas. Mice were dark adapted for $12 \mathrm{~h}$, and the retinas were isolated from the sclera and pigment epithelium under infrared light $(>950 \mathrm{~nm})$ following procedures approved by the Administrative Panel on Laboratory Animal Care at the University of Washington. Retinas were stored in the dark at $32^{\circ} \mathrm{C}$ in bicarbonatebased Ames solution (Sigma, St. Louis, $\mathrm{MO}$ ) equilibrated with $5 \% \mathrm{CO}_{2} /$ $95 \% \mathrm{O}_{2}$. Primate retina was obtained through the Tissue Distribution Program of the Regional Primate Research Center at the University of Washington. Pieces of retina not well attached to the pigment epithelium were discarded, and the remaining retina was dark adapted for $1 \mathrm{~h}$ at $32^{\circ} \mathrm{C}$ and then prepared identically to mouse retina. During all recordings, cells were continuously superfused with Ames solution warmed to $34-37^{\circ} \mathrm{C}$.

Recording procedures and cell types. Rod photoreceptor currents were recorded using suction electrodes (Baylor et al., 1979a; Field and Rieke, 2002a). Measured outer segment currents were low-pass filtered at $30 \mathrm{~Hz}$ and digitized at $1 \mathrm{kHz}$. Under our recording conditions, rod responses to 10 ms flashes producing an average of $\sim 1$ photoisomerization $\left(\mathrm{Rh}^{*}\right)$ per rod were consistently more sensitive (single-photon response amplitude at $37^{\circ} \mathrm{C}, 1.07 \pm 0.09 \mathrm{pA}$, mean $\left.\pm \mathrm{SEM} ; N=17\right)$ and longer lasting (time-to-peak, $218 \pm 6 \mathrm{~ms}$ ) than reported previously for mouse rods (Burns et al., 2002; Makino et al., 2004). Correspondingly, the gain of the rod responses declined at lower backgrounds than observed previously (Makino et al., 2004). Reasons for differences in sensitivity are unknown.

Responses of rod bipolar cells, AII amacrine cells, and $\alpha$ ganglion cells were recorded in 200- $\mu \mathrm{m}$-thick retinal slices, prepared following procedures described previously (Field and Rieke, 2002b; Armstrong-Gold and Rieke, 2003). Neurons at a depth of 30-50 $\mu \mathrm{m}$ were targeted to minimize the effects of slicing on the recorded cell. As a control, ganglion cell responses measured in slices were compared with those in a flatmount preparation. Ganglion cell responses should be most affected by slicing because they have the most extensive dendrites of the cells studied and rely on all upstream cells functioning properly. Half-maximal flash strengths for $\alpha$ ganglion cells in slice and flat-mount preparations differed by less than a factor of 2 and were similar to those in other studies (Deans et al., 2002; Pang et al., 2003; Volgyi et al., 2004).

Rod bipolar responses were measured using perforated-patch recordings. The internal solution contained $125 \mathrm{~mm} \mathrm{~K}$-aspartate, $10 \mathrm{~mm} \mathrm{KCl}, 10$ mM HEPES, 5 mm $N$-methyl-D-glucamine (NMG) $-N$-hydroxyethylethylene diaminetriacetic acid, $1 \mathrm{~mm} \mathrm{MgCl}_{2}, 0.5 \mathrm{~mm} \mathrm{CaCl}, 4 \mathrm{~mm}$ ATP-Mg, $0.5 \mathrm{~mm}$ GTP-Tris, and $0.05 \mathrm{mg} / \mathrm{ml}$ amphotericin-B; $\mathrm{pH}$ was adjusted to 7.2 with NMG-OH, and osmolarity was $\sim 280 \mathrm{mOsm}$. Synaptic currents of AII amacrine and ganglion cells were measured using whole-cell recordings. The internal solution contained the following (in $\mathrm{mM}$ ): $90 \mathrm{CsCH}_{3} \mathrm{SO}_{3}, 20$ tetraethylammonium (TEA)-Cl, 10 HEPES, $10 \mathrm{Cs}_{2}$-EGTA, 10 sodium phosphocreatine, 2 QX314 [N-(2,6-dimethylphenylcarbamoyl-methyl) triethylammonium bromide] bromo, 4 ATP, and 0.5 Mg-GTP. Cesium, TEA, and QX314 suppressed potassium and sodium currents, reducing voltage-clamp errors. In some recordings, we used 10 rather than $20 \mathrm{~mm}$ TEA-Cl and increased the $\mathrm{CsCH}_{3} \mathrm{SO}_{3}$ concentration to maintain the osmolarity; the lower chloride concentration did not noticeably alter any of the results reported here. Current was low-pass filtered at $3 \mathrm{kHz}$ and digitized at $10 \mathrm{kHz}$. Junction potentials (approximately $-10 \mathrm{mV}$ for the cesium internal and -2 $\mathrm{mV}$ for the potassium internal) have not been corrected.

AII amacrine cells were identified by a large primary neurite protruding into the inner plexiform layer and vigorous spontaneous activity in the dark. $\alpha$ ganglion cells had the largest somata of cells in the ganglion cell layer, sustained responses to light steps (Pang et al., 2003), and high sensitivity. Identification of rod bipolar cells, AII amacrine cells, and $\alpha$ ganglion cells was confirmed in early recordings by including Alexa Fluor-488 (Invitrogen, Carlsbad, CA) in the internal solution and imaging the morphology of the cell under fluorescence. Primate ganglion cells with the largest somata were targeted, but cell type was not determined.

Based on current-clamp recordings with the potassium internal, rod bipolar and AII amacrine cells had resting membrane potentials of $-58 \pm 2 \mathrm{mV}($ mean $\pm \mathrm{SEM} ; N=16)$ and $-46 \pm 1.6 \mathrm{mV}(N=8)$, pipette series resistances of $90 \pm 10 \mathrm{M} \Omega(N=6)$ and $80 \pm 20 \mathrm{M} \Omega(N=6)$, and input resistances of $1200 \pm 100$ and $420 \pm 70 \mathrm{M} \Omega$.

Light stimuli. Unpolarized light stimuli were delivered from lightemitting diodes (LEDs) with peak output wavelengths of $470 \mathrm{~nm}$ (10 ms flashes) and $513 \mathrm{~nm}$ (background light) focused through the microscope condenser. Stimuli covered a $630-\mu \mathrm{m}$-diameter circle centered on the recorded cell. Calibrated photon fluxes (photons per square micrometer per second) were converted to $\mathrm{Rh}^{\star} / \mathrm{rod} / \mathrm{s}$ based on the rod spectral sensitivity, measured LED spectrum, and a collecting area of $0.5 \mu \mathrm{m}^{2}$ for slice and flat-mount preparations (Field and Rieke, 2002b). For slice recordings, these calibrations could be overestimates because light stimuli had to traverse other rods before reaching those providing input to the recorded cell. To check for such screening effects, we compared stimulus-response relationships produced by flashes that are absorbed well by the rods $(513 \mathrm{~nm})$ with those absorbed poorly $(570 \mathrm{~nm})$. In AII amacrine cells, the half-maximal flash strengths for stimulus-response relationships produced by 513 and $570 \mathrm{~nm}$ lights were not significantly different when corrected for the rod spectral sensitivity (two-sample $t$ test, $t=$ $0.05 ; p>0.1$ ) (Field and Rieke, 2002b). The total light delivered in the longest recording bleached $<0.05 \%$ of the rhodopsin molecules of a rod.

Rods, AII amacrine cells, and ganglion cells were stimulated with two to three flash strengths to test for linearity (see below). The weakest flash was chosen to evoke responses that were difficult to identify on individual trials but clearly discernable when averaged over 10-30 trials; subsequent flash strengths increased by a factor of 2 . Rod bipolar cells were stimulated with a single flash producing $0.1-0.3 \mathrm{Rh}^{\star} /$ rod. These flashes rarely produced more than one absorbed photon in individual rods, and hence the rod bipolar responses depended linearly on flash strength. Saturating flashes were delivered periodically to check for changes in the maximal light response. Gain and noise measured in the presence of a background were scaled by the average of earlier and later measurements in darkness to avoid confounding a true gain change with a timedependent change in the recording.

Stimulus-response relationships. The dependence of response amplitude on flash strength for rods was fit with a saturating exponential. Stimulus-response relationships for rod bipolar, AII amacrine, and ganglion cells were fit with the following Hill equation:

$$
\frac{R}{R_{\max }}=\frac{1}{1+\left(\phi_{\text {half }} / \phi\right)^{n}},
$$

where $R / R_{\max }$ is the normalized response amplitude, $\phi_{\text {half }}$ is the halfmaximal flash strength, and $n$ is the Hill exponent describing the relationship between the response amplitude and flash strength, $\phi$.

Measuring gain and noise. Gain and noise were measured from sections of record with (response trials) and without (noise trials) a flash (see Fig. 2). We reduced each response and noise trial to a single number: its correlation with a template formed from the average of all dim flash responses. The template was normalized such that the correlation of the template with itself was 1 . The correlation of an individual response with the template provides a measure of the scale factor required to match the template to the response, i.e., a measure of response amplitude that is insensitive to noise except that with a time course resembling the flash response. These correlations were used to measure the background dependence of response gain. A different template was used at each background to account for background-induced changes in response kinetics. Such changes in kinetics were small over the range of backgrounds tested, and fixing the template produced less than a $30 \%$ change in the backgrounds required to halve gain.

The mean of the noise trial correlations with the template was 0 , and the mean of the response trial correlations was $m_{\text {flash }}=f g$, where $f$ is the flash strength in $\mathrm{Rh}^{\star}$ per rod, and $g$ is the gain of the response of the cell. We averaged estimates of the gain $\left(g=m_{\text {flash }} / f\right)$ across several flash strengths. We defined the gain in darkness to be 1 and scaled the response and noise correlations at all backgrounds accordingly: all response and noise correlations were measured relative to the average correlation produced by a flash in darkness with a strength of $1 \mathrm{Rh}^{\star} /$ rod. 
The variance of the noise correlations we define as the flashindependent noise, $\sigma_{\text {flash-indep }}{ }^{2}$. The variance of the flash correlations exceeding $\sigma_{\text {flash-indep }}{ }^{2}$ (i.e., noise attributable to the flash response itself), we define as $\sigma_{1 \mathrm{Rh}^{*}}{ }^{2}$. Assuming that the two noise sources are independent and additive, the total variance of the flash correlations is as follows:

$$
\sigma_{\text {total }}{ }^{2}=\sigma_{\text {flash-indep }}{ }^{2}+f \sigma_{1 \mathrm{Rh}^{*}}{ }^{2},
$$

where $\sigma_{1 \mathrm{Rh}}{ }^{2}$ estimated for a flash strength of $1 \mathrm{Rh}^{*} /$ rod has been scaled by the flash strength $f$, as expected for Poisson fluctuations in the number of photon absorptions produced by the flash.

Flash-dependent noise, $\sigma_{\text {flash-dep }}$, was defined as the noise attributable to the flash response at threshold, i.e., at each background, it was equal to $\sqrt{f_{T} \sigma_{1 \mathrm{Rh}}{ }^{2}}$ for $f_{T}$ given by Equation 4 below. This is the square root of the second term in Equation 2. This choice of scaling allowed the impact of flash-dependent and flash-independent noise on detection threshold to be compared directly (see Figs. 3-5).

The procedure described above relied on response amplitude and the noise attributable to the flash response scaling linearly with flash strength. We checked this assumption by comparing gain and noise estimated from responses to each individual flash strength (see Fig. $3 A-C$, open symbols) with the averages (filled circles). Estimates of gain, flashindependent, and flash-dependent noise did not depend systematically on flash strength for any of the cells studied.

Definition of threshold. Threshold was defined for a flash/no-flash twointerval forced-choice task. The task was to identify the response trial given one response trial and one noise trial. We based this decision on the correlations of the response and noise trials with the template, as described above.

A simple decision rule in the two-interval task described above is to identify the response trial as that generating a larger correlation, i.e., the discrimination signal is the difference between response and noise correlations. This is the optimal strategy in the case of Gaussian distributions with equal variance, conditions that held approximately for nearthreshold responses in the ganglion cells. The distribution of the differences between response and noise correlations has a mean amplitude, $m_{\text {flash }}=f g$, and a variance equal to the sum of the response and noise variances, i.e., $2 \sigma_{\text {flash-indep }}{ }^{2}+f \sigma_{1 \mathrm{Rh}}{ }^{2}$; hence, the signal-to-noise ratio (SNR) is as follows:

$$
\mathrm{SNR}=\frac{f g}{\sqrt{2 \sigma_{\text {flash-indep }}^{2}+f \sigma_{1 \mathrm{Rh}^{*}}}},
$$

Threshold was defined as the flash strength at which the signal-to-noise ratio was 1 , as follows:

$$
f_{T}=\text { Threshold }=\frac{\sigma_{1 \mathrm{Rh}^{*}}{ }^{2}+\sqrt{\sigma_{1 \mathrm{Rh}^{*}}{ }^{4}+8 g^{2} \sigma_{\text {flash-indep }}{ }^{2}}}{2 g^{2}} .
$$

The threshold calculation relied on estimates of signal and noise at flash strengths that were not probed directly. To check the accuracy of this interpolation, we compared thresholds estimated for each individual flash strength (see Fig. $3 D$, open symbols) with the averages (filled circles). The estimated threshold did not depend systematically on flash strength for any of the cells studied.

Fits to gain, noise, and threshold. Gain, flash-independent noise, and flash-dependent noise were fit empirically with a function chosen for its applicability across cell types and its simplicity in quantifying the dependence of gain on background:

$$
\text { fit }=\left(\frac{|a|+b I_{B}}{|a|+I_{B}}\right)\left(c I_{B}+1\right)^{m} d .
$$

The first term is needed to account for the slight gain increase seen in the AII amacrine and ganglion cell responses at low backgrounds. $I_{B}$ is the mean background intensity, $a$ determines the backgrounds at which gain increases, and $b$ determines the maximum asymptotic value. The second term describes a gain decrease, where $c$ determines the background at which gain decreases, $m$ describes the dependence of gain on background, and $d$ is a vertical scaling factor. Each data point was weighted inversely by the SEM. In some cases, one or more parameters were fixed (see figure legends), e.g., $d$ was 1 for fits to the gain.

Ganglion cell threshold was fit to estimate the rate of increase in threshold with background $I_{B}$ and the background at which threshold began to increase, the intrinsic dark light $I_{D}$ (Barlow, 1957):

$$
\text { Threshold }=K\left(I_{B}+I_{D}\right)^{M} \text {. }
$$

$M$ is the slope on double logarithmic coordinates, and $K$ is a vertical scale factor.

Ideal-observer model. The ideal-observer model predicted the sensitivity limit set by noise in the responses of the collection of rods providing input to a ganglion cell. The model consists of two components: a description of the responses of a single rod to a dim flash in the presence of a background and a model for how responses were combined to provide input to the ganglion cell.

The model for responses of a single rod predicted noise (no-flash) and signal (flash) distributions given a flash strength and background intensity. Three noise sources contribute in the absence of a flash: (1) continuous noise produced in the rod phototransduction cascade (Baylor et al., 1980; Rieke and Baylor, 1996); (2) discrete noise attributable to spontaneous isomerization of rhodopsin (Baylor et al., 1980, 1984); and (3) quantal fluctuations produced by the background light. The distribution of responses in the presence of a flash includes additional noise from variability in the single-photon response (Rieke and Baylor, 1998; Whitlock and Lamb, 1999; Field and Rieke, 2002a) and quantal fluctuations produced by the flash itself. We assumed these noise sources were independent and additive.

A single rod flash or no-flash trial was generated in three steps. In the first step, continuous noise was generated by filtering Gaussian white noise with a four-stage, low-pass filter $\left(A t^{3} e^{-t / \tau}\right)$, where $\tau=0.08 \mathrm{~s}$, and $A$ set the continuous noise amplitude. This simulated continuous noise at temporal frequencies that interfered with detection of a flash response (see below). In the second step, thermal isomerizations and quantal fluctuations from background light were added. Both of these noise sources produce randomly timed discrete responses with an average shape identical to the single-photon response. The single-photon response was described as the output of the same four-stage, low-pass filter used in generating continuous noise (Baylor et al., 1979b, 1984). The number of discrete responses was determined from a Poisson distribution with a mean equal to the event rate multiplied by the duration of the simulated trial. The amplitude of each event was determined by drawing from a Gaussian distribution. In the third step, the number of photon absorptions produced by the flash was determined from a Poisson distribution with a mean equal to the flash strength in $\mathrm{Rh}^{\star}$ per rod. Responses to each absorbed photon were simulated from the four-stage filter model and summed. This last step was omitted for no-flash trials. These three steps produced a single example of the rod response at a given background and flash strength.

Parameters of the modeled single-photon responses were based on previous measurements (Field and Rieke, 2002b): the single-photon response amplitude was 1 and its SD was 0.33 . The continuous dark noise had an SD of 0.40 (see Fig. 6D). Discrete noise events were assumed to occur at a rate of $0.012 \mathrm{~s}^{-1}$ (Burns et al., 2002). These parameters were taken to be identical with each background, which restricts the model to backgrounds for which rod gain was near 1 (i.e., $<5 \mathrm{Rh}^{\star} / \mathrm{rod} / \mathrm{s}$ from Fig. $6 C)$.

Each rod flash or no-flash response was weighted by a nonlinearity described by a cumulative Gaussian with a mean of 1.3 and SD of 0.1 (Field and Rieke, 2002b). These parameters were consistent with bipolar gain increases in Figure $7 C$. This procedure was repeated to generate a collection of nonlinearly weighted flash and no-flash responses. Consistent with analysis of experimental data, each such response was characterized by correlation with a template given by the average flash response. These correlations formed the signal and noise distributions for a single rod.

To generate the signal and noise distributions for a ganglion cell, we convolved the rod signal and noise distributions with themselves. Convolution is equivalent to linear summation of individual draws from the 
distribution. The signal and noise distributions were convolved to generate distributions of $N$ samples, thus reducing the ganglion cell receptive field to a disc in which each rod signal is equally weighted. $N$ was estimated by summing the rod weights for a two-dimensional Gaussian receptive field profile and multiplying by 2 to account for differences in how signal and noise sum [to compare a Gaussian with an equivalent disc receptive field, see Hemila et al. (1998), their Eqs. 5 and 15]. We assumed that $\sim 5000$ rods fell within the $\alpha$ ganglion cell receptive field, at the low end of the estimates of 5000-20,000 from past work (Stone and Pinto, 1992; Sinclair et al., 2004). We assumed that half of the ganglion cell receptive field ( $\sim 2500$ rods $)$ is retained in a $200 \mu \mathrm{m}$ slice and thus used $N=4096$ rods for an equivalent disc profile. The mean and SD of the resulting signal and noise distributions were used to estimate flashindependent and flash-dependent noise according to Equation 2 and threshold according to Equation 4. Calculation of threshold assumed Gaussian signal and noise distributions; actual distributions closely resembled Gaussians because of the high degree of rod convergence.

\section{Results}

We start by identifying the elements of the rod bipolar pathway that are most susceptible to saturation as light levels increase. We then characterize the impact of background light on the gain and noise of the responses of cells across the rod bipolar pathway to determine where gain is controlled and how sensitivity is affected. Finally, we use an ideal-observer model to test the location and magnitude of the noise source(s) limiting ganglion cell sensitivity.

\section{Convergence, saturation, and placement of gain control}

In all adapting circuits, convergence and amplification dictate how effectively sensitivity is preserved by gain controls operating at different locations. Thus, the increasing rod convergence at each successive stage of the rod bipolar pathway (Fig. 1A) (Sterling et al., 1988) improves the fidelity of rod-mediated signals by averaging across rods but also presents an increasing risk of saturation.

At light levels near the onset of adaptation $\left(\sim 0.1 \mathrm{Rh}^{\star} / \mathrm{rod} / \mathrm{s}\right.$; see below), AII amacrine cells are the first cells in the rod bipolar pathway that receive overlapping single-photon responses. Thus, in the $\sim 200 \mathrm{~ms}$ integration time $(\tau)$ of rod signals, rods rarely absorb more than one photon $\left(\sim 0.02 \mathrm{Rh}^{\star} / \operatorname{rod} / \tau\right)$. The same is true of the collection of $\sim 20$ rods providing input to a rod bipolar cell $\left(\sim 0.4 \mathrm{Rh}^{\star} / \operatorname{rod}\right.$ bipolar$\left./ \tau\right)$. AII amacrine cells, however, receive indirect input from $\sim 500$ rods, several of which are likely to absorb photons in a $200 \mathrm{~ms}$ period $\left(\sim 10 \mathrm{Rh}^{\star} / \mathrm{AII}\right.$ amacrine $\left./ \tau\right)$. Thus, convergence together with the amplification required for detecting a small number of photons suggests that the gain of rod-mediated signals needs to be controlled before the AII amacrine cell integrates its inputs.

As suggested by convergence, responses of AII amacrine cells were subject to saturation at lower light levels than those of rods or rod bipolar cells. Figure $1 B$ shows average stimulus-response relationships for rods, rod bipolar cells, AII amacrine cells, and ON $\alpha$ ganglion cells. Stimulus-response relationships were measured from average responses to brief flashes delivered in darkness. Two properties of the stimulus-response relationships highlight the importance of controlling gain before the AII integrates its inputs. First, rods and rod bipolar cells were capable of encoding much brighter flashes than AII amacrine cells and oN $\alpha$ ganglion cells; half-saturating flash strengths were $>1 \mathrm{Rh}^{\star} /$ rod for both rods and rod bipolar cells and $\sim 0.1 \mathrm{Rh}^{\star} /$ rod for AII amacrine and ganglion cells (for details, see figure legend). Thus, avoiding saturation as light levels increase requires lowering the gain of rod-mediated signals before the AII amacrine cell. Sec-

\section{A Rod bipolar pathway}
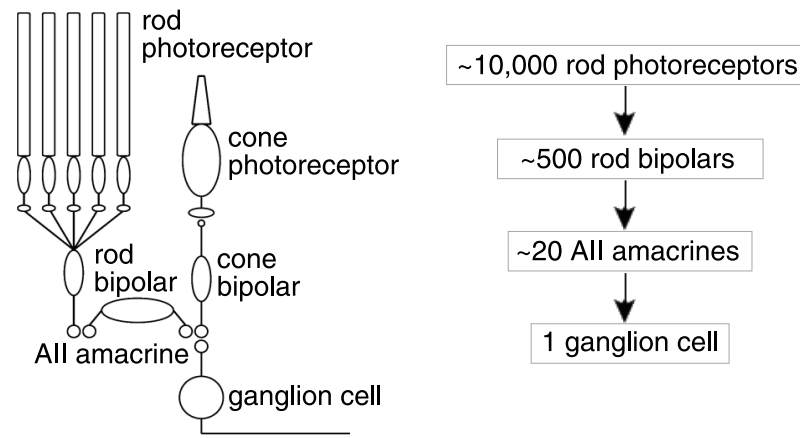

B

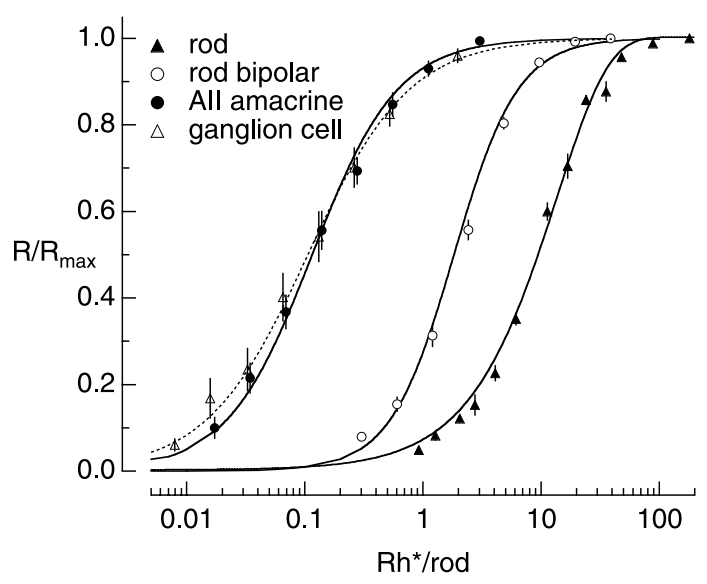

Figure 1. Stimulus-response relationships for cells in the rod bipolar pathway. $\boldsymbol{A}$, Schematic of the mammalian rod bipolar pathway and estimates of convergence [cat (Sterling et al., 1988); mouse (Tsukamoto et al., 2001)]. Most synapses are glutamatergic, with the exceptions of electrical coupling between the All amacrine and on cone bipolar, and a glycinergic synapse between the All amacrine and off cone bipolar (Strettoi et al., 1992) (for review, see Bloomfield and Dacheux, 2001). B, Stimulus-response relationships for cells across the rod bipolar pathway in mouse retina. Points plot average responses (mean \pm SEM) to a 10 ms flash delivered in darkness. The rod stimulus-response relationship was fit with a saturating exponential with $\phi_{\text {half }}=9.6 \pm 0.2 \mathrm{Rh}^{*}(N=22)$. Stimulus-response relationships for on $\alpha$ ganglion cells, All amacrine cells, and rod bipolar cells were fit with a Hill curve (Eq. 1). Half-saturating flash strengths, $\phi_{\text {half }}$, and the exponent, $n$, were $\phi_{\text {half }}=1.83 \pm 0.06 \mathrm{Rh}^{*} /$ rod and $n=1.6 \pm 0.04$ for rod bipolar cells $(N=43), \phi_{\text {half }}=0.12 \pm 0.01 \mathrm{Rh}^{*} / \mathrm{rod}$ and $n=1.20 \pm 0.06$ for All amacrine cells $(N=12)$, and $\phi_{\text {half }}=0.11 \pm 0.01 \mathrm{Rh}^{*} / \mathrm{rod}$ and $n=1.01 \pm 0.06$ for ganglion cells $(N=9)$.

ond, responses of AII amacrine cells and on $\alpha$ ganglion cells had a similar dependence on flash strength. Thus, substantial postAII gain controls may not be required to protect ganglion cell responses from saturating.

\section{Measuring gain, noise, and threshold}

The stimulus-response relationships in Figure $1 B$ highlight the need for a gain control that protects the AII amacrine responses from saturation. To test this prediction and to characterize gain control, we measured the effect of background lights on the responses of cells throughout the rod bipolar pathway. We start by explaining how we quantified response gain, noise, and sensitivity.

Figure 2 illustrates our analysis based on recordings from a voltage-clamped mouse on $\alpha$ ganglion cell. Measuring ganglion cell synaptic currents rather than output spike trains permitted direct comparisons with responses of other retinal cell types. Figure $2 \mathrm{~A}$ shows four responses to a dim flash with no background, and Figure $2 D$ shows four noise trials, i.e., sections of recording 

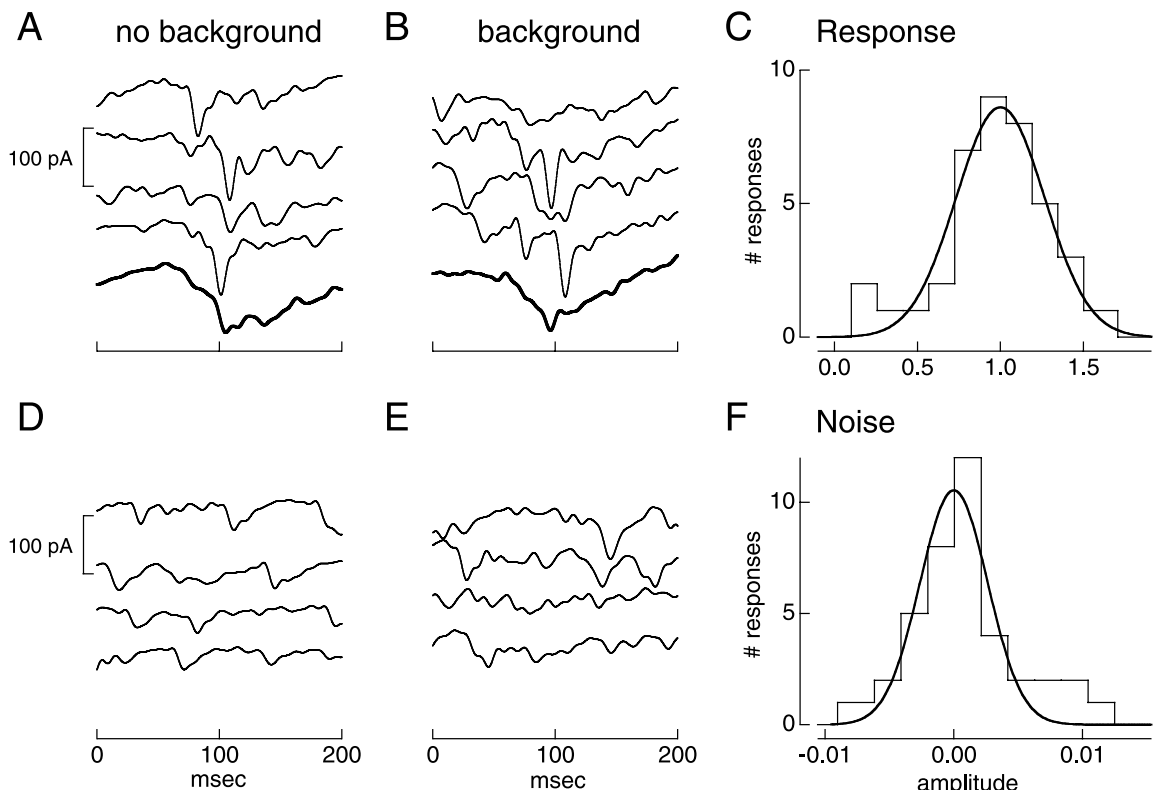

E

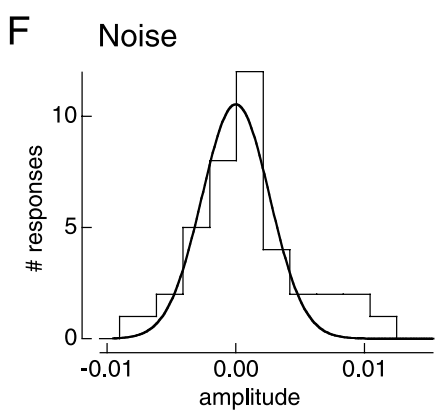

Figure 2. Procedure for measuring signal and noise. $\boldsymbol{A}$, Four current responses of a mouse on $\alpha$ ganglion cell to a flash producing on average $0.02 \mathrm{Rh}$ */rod delivered at time 0 with no background. Template (thick trace) is the average of 28 responses. Holding potential was $-60 \mathrm{mV}$. Filtered at $100 \mathrm{~Hz}$. $\boldsymbol{B}$, Four responses to a flash producing on average $0.06 \mathrm{Rh} / \mathrm{rod}$ with a background of $0.6 \mathrm{Rh}^{*} / \mathrm{rod} / \mathrm{s}$. Template (thick trace) is the average of 28 responses. $\boldsymbol{C}$, Distribution of correlations between the template and responses to a flash producing on average $1 \mathrm{Rh}^{*} /$ rod in darkness $(N=39)$. Thick trace is a Gaussian fit (mean \pm SD, $1.09 \pm 0.52)$. $\boldsymbol{D}$, Noise trials in darkness. $\boldsymbol{E}$, Noise trials on the same background in $\boldsymbol{B}$. $\boldsymbol{F}$, Distribution of the correlations between the noise trials with no background $(N=39)$ and the template. Thick trace is a Gaussian fit (SD of 0.0089). The SD of the noise distribution defines the flash-independent noise.

without a flash. Figure 2, $B$ and $E$, shows response and noise trials at a background intensity of $0.6 \mathrm{Rh}^{\star} / \mathrm{rod} / \mathrm{s}$. We measured the amplitude of each response trial and each noise trial from its correlation with a template formed from the average dim flash response (Fig. 2A, B, thick traces) (see Materials and Methods). Figure 2, $C$ and $F$, shows the distribution of correlations for the response and noise trials measured with no background. Response correlations were scaled by the flash strength and normalized by the mean response correlation in darkness. This scaling meant that response and noise correlations were measured relative to the mean correlation produced by a $1 \mathrm{Rh}^{\star} /$ rod flash in darkness, e.g., noise in Figure $2 F$ is $<0.01$ times the amplitude of the response to a flash producing $1 \mathrm{Rh}^{\star} / \mathrm{rod}$. Reductions in response amplitude (e.g., attributable to background light) reduced the response correlation.

Distributions like those in Figure 2, $C$ and $F$, were measured at several backgrounds and used to estimate response gain and noise, as in Figure 3. Figure $3 A$ shows the background dependence of response gain, defined as the mean of the response trial correlations (Fig. 2C). Two types of noise obscured the flash responses: flash-independent background noise and noise attributable to the flash itself. Flash-independent noise (Fig. 3B) was attributable to cellular dark noise and quantal fluctuations produced by the background; it was measured directly from the SD of the noise trial correlations (Fig. $2 F$ ). We made no assumptions about the shape of this distribution except in the definition of threshold below. Noise attributable to the flash was caused by quantal fluctuations produced by the flash and cellular variability in the generation and transmission of the flash response; it was measured by correcting variability in the flash response (Fig. 2C) for flash-independent noise, assuming that the two types of noise were independent and additive. Figure $3 C$ plots the noise attrib- utable to the flash at detection threshold, which we define as flash-dependent noise (see below and Materials and Methods).

We measured the impact of gain and noise on sensitivity in the context of a flash/no-flash discrimination task, i.e., from the ability to identify correctly the response trial given one response and one noise trial. Assuming that the noise was Gaussian, threshold was defined as the flash strength producing a signal-to-noise ratio of 1 (Fig. 3D) (Eq. 4). For Gaussian distributions, this definition of threshold corresponds to the flash strength producing $76 \%$ correct discrimination performance (chance performance in this task is $50 \%)$.

\section{Gain, noise, and threshold in ganglion cells}

The analysis illustrated in Figures 2 and 3 was used to determine how gain, noise, and threshold depended on background light for cells throughout the rod bipolar pathway. We start by describing measurements from primate and mouse retinal ganglion cells.

\section{Primate}

A long history of behavioral work characterizes how weak background lights change the threshold of rod vision (for review, see Barlow, 1957; Donner, 1992). The physiological basis of these changes in behavioral threshold is unclear; although the effect of weak backgrounds on the electroretinogram (ERG) has been measured in primates (Frishman and Sieving, 1995), we know little about how weak backgrounds alter signal and noise in individual cells in primate retina. The experiments described below show that dim backgrounds cause the gain of primate ganglion cell responses to decrease whereas the noise remains relatively constant; these properties are similar to findings from previous extracellular recordings in cat (Barlow and Levick, 1969).

Figure 4 summarizes measurements from eight primate ON ganglion cells. Gain increased slightly $(\sim 5 \%)$ for the weakest backgrounds tested. Gain began to decrease at backgrounds $I_{B}$ near $0.2 \mathrm{Rh}^{*} / \mathrm{rod} / \mathrm{s}$ and fell more gradually than the $1 / I_{B}$ expected for Weber adaptation (Fig. $4 \mathrm{~A}$, legend). Both flash-independent (Fig. $4 B$ ) and flash-dependent (Fig. 4C) noise began to increase near $0.2 \mathrm{Rh}^{\star} / \mathrm{rod} / \mathrm{s}$, similar to the background at which gain began to decrease (Fig. $4 B$ ). Changes in both types of noise, however, were substantially smaller than changes in gain $(<3$-fold change in noise vs 20 -fold change in gain between darkness and $60 \mathrm{Rh}^{\star} / \mathrm{rod} / \mathrm{s}$ ). Measurements of gain and noise were used to determine the dependence of threshold on background (Fig. 4D) (Eq. 4). Threshold exhibited a background-independent region for backgrounds below $0.1 \mathrm{Rh}^{\star} / \mathrm{rod} / \mathrm{s}$ and then increased as $I_{B}{ }^{0.6}$ (Fig. 4D, smooth curve, exponent $0.6 \pm 0.1$ ).

\section{Mouse}

To determine where the gain of rod-mediated responses is controlled in the retina, we measured the effect of background lights on the responses of cells throughout the rod bipolar pathway in mouse. Mouse shares the conserved rod bipolar pathway with 
A

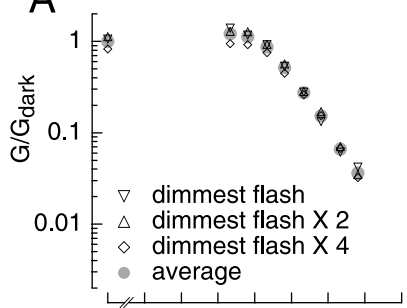

C

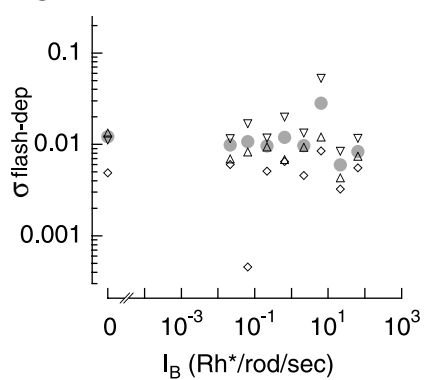

B

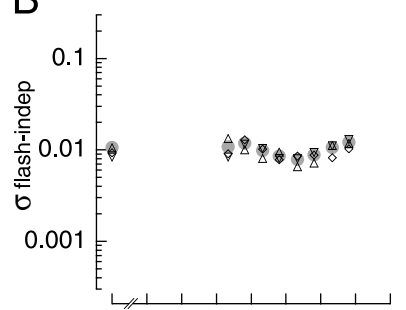

D

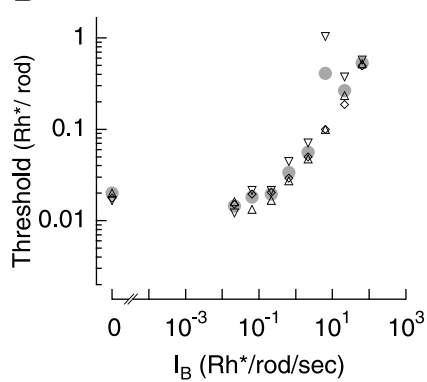

Figure 3. Gain, noise, and threshold for a single mouse ganglion cell. $A$, Gain estimated from consecutive responses to three flash strengths (open symbols) and averaged across flash strengths and repeated measurements (filled circles) for several background intensities. Gain was defined as the mean of the response trial correlations (see Fig. 2C). B, Flash-independent noise for several backgrounds. Flash-independent noise was defined as the SD of correlations between noise trials and the template (see Fig. 2F). C, Flash-dependent noise for several backgrounds. Flash-dependent noise measures the variability attributable to the flash itself (i.e., the variability remaining after subtracting flash-independent noise). Flash-dependent noise was estimated for a flash strength equal to detection threshold (see $\boldsymbol{D}$ and Materials and Methods). D, Threshold for several backgrounds, calculated according to Equation 4. The threshold represents the flash strength ( $\mathrm{Rh}^{*}$ per rod) at which the signal-to-noise ratio for a flash/no-flash two-interval forced-choice experiment is 1 (see Materials and Methods).

other mammalian retinas and offers several technical advantages, including the use of genetic manipulations to investigate mechanisms (see below). We start with the ganglion cells.

Figure 5 summarizes measurements from 16 mouse oN $\alpha$ ganglion cells in the slice preparation and 13 cells in the flat-mount preparation. Gain began to decrease at backgrounds near 0.3 $\mathrm{Rh}^{\star} / \mathrm{rod} / \mathrm{s}$ and fell more gradually than expected for Weber adaptation (Fig. 5A). Gain began to fall at similar backgrounds in both slice and flat-mount preparations, indicating that slicing did not disrupt the gain control operating at the lowest background. We focus on the slice data below because it can be compared directly with other cells in the rod bipolar pathway.

Flash-independent and flash-dependent noise changed less than threefold for backgrounds up to $500 \mathrm{Rh}^{*} / \mathrm{rod} / \mathrm{s}$ (Fig. $5 B, C$ ); over the same range of backgrounds, response gain decreased $>100$-fold. Gain and noise were used to calculate threshold, which increased as $I_{B}{ }^{0.76}$ (Fig. $5 D$, exponent of $0.76 \pm 0.08$ ).

\section{Changes in gain dominate changes in threshold}

The dependence of threshold on background light for mouse and primate ganglion cells did not differ noticeably (Fig. $5 D$ ). In both species, background lights produced much larger changes in gain than noise, and hence the dependence of threshold on background resembled the inverse of the response gain. Thus, gain changes, rather than changes in noise, dominated changes in threshold. Barlow and Levick (1969) reached a similar conclusion from extracellular recordings in cat ganglion cells.

The gain changes in Figures $4 A$ and $5 A$ could reflect adaptive changes in sensitivity or compression attributable to a background-induced reduction in the range of signals a ganglion
A

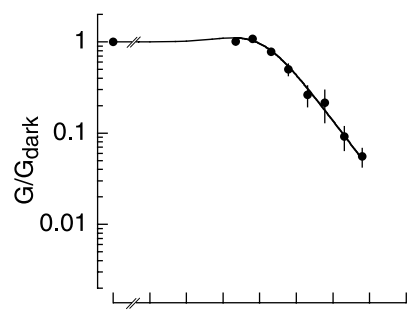

B
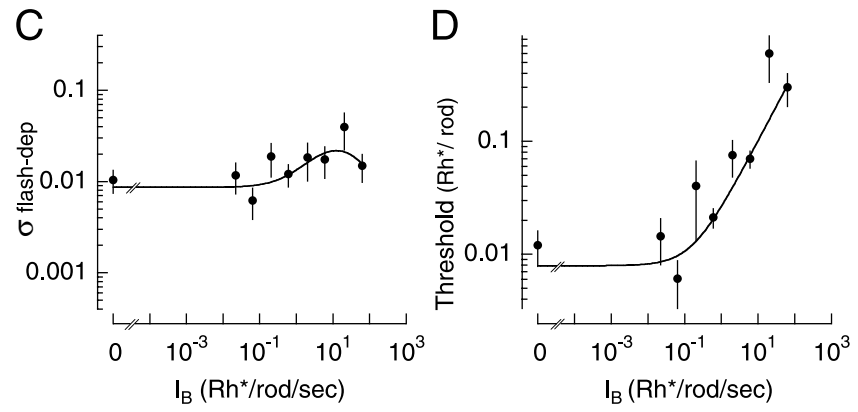

Figure 4. Gain, noise, and threshold of primate ganglion cells. $A$, Dependence of gain on background. Collected current responses (mean \pm SEM) from eight primate on ganglion cells. Smooth fit from Equation 5 with exponent $m=-0.53 \pm 0.06$ (mean \pm SD), $a=0.01, b$ fixed at $1.3, c=7.1$, and $d$ fixed at 1. Error bars represent SEM. Measurements at backgrounds that differed by $<30 \%$ were averaged together. Voltage clamped at $-60 \mathrm{mV}$. B, Dependence of flash-independent noise on background. Smooth fit from Equation 5 with parameters $a=4.4$, $b=3.7$, c fixed at $1, d=0.004$, and $m$ fixed at 0 . C, Dependence of flash-dependent noise on background. Smooth fit from Equation 5 with parameters $a=23, b=27, c=0.56, d=0.01$, and $m=-0.67$. D. Dependence of threshold on background. Smooth fit from Equation 6 with $M=0.6 \pm 0.1$ (mean $\pm S D), I_{D}=0.16$, and $K=0.02$.

cell could produce. Two observations indicated that the gain changes were attributable to neural adaptation. First, backgrounds that halved gain reduced the response to a bright flash ( $\sim 100$ times the typical test flash) by $<20 \%$. Second, gain changes after increases and decreases in background light did not occur instantaneously but instead required $\sim 500 \mathrm{~ms}$ to complete (data not shown).

Figures 4 and 5 illustrate three key properties of adaptation and threshold in primate and mouse ganglion cells: (1) adaptation reduced the gain of rod-mediated signals for backgrounds above $0.2 \mathrm{Rh} / \mathrm{rod} / \mathrm{s}$; (2) flash-independent and flash-dependent noise made similar contributions to threshold and were both relatively insensitive to background; and (3) changes in threshold with background were dominated by changes in gain rather than noise.

\section{Primary site of adaptation is rod bipolar-to-AII amacrine synapse}

The ganglion cell results described above indicate that the gain of rod-mediated signals is controlled somewhere in the retina. The stimulus-response relationships in Figure $1 B$ indicate that such a gain control should be located before the AII amacrine cell to prevent saturation of the AII responses. To test this prediction, we measured the gain and noise of cells across the rod bipolar pathway: rods, rod bipolar cells, and AII amacrine cells. We focused on gain and flash-independent noise because they provide a clear signature of adaptation: gain should begin to decrease at backgrounds near $0.2-0.3 \mathrm{Rh}^{\star} / \mathrm{rod} / \mathrm{s}$, and flash-independent noise should be relatively constant across backgrounds. As described below, these experiments identified the rod bipolar-to- 

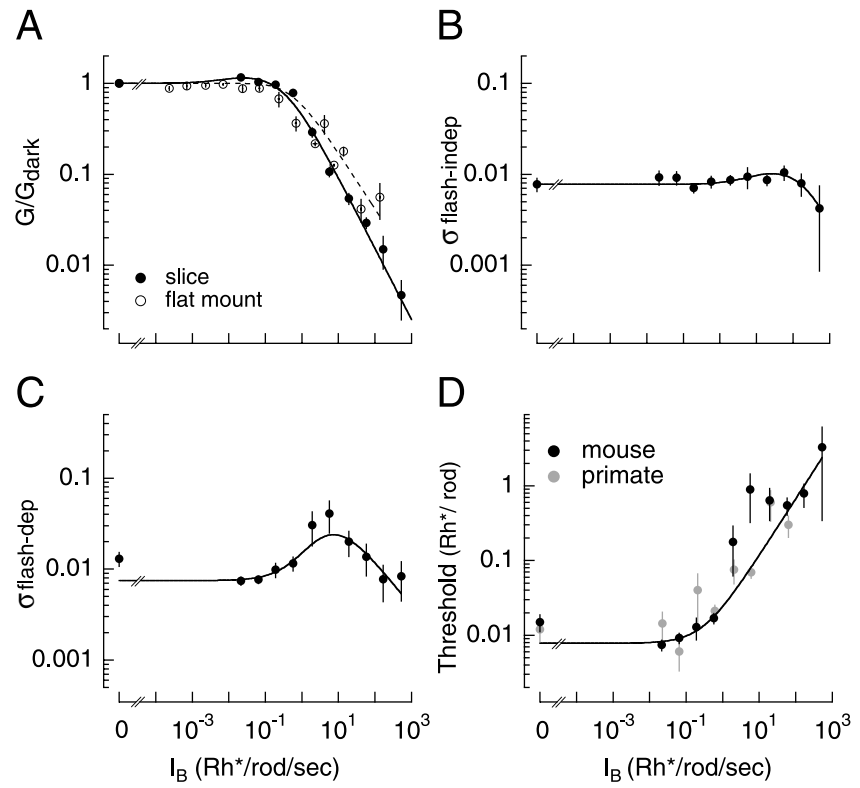

Figure 5. Gain, noise, and threshold of mouse on $\alpha$ ganglion cells. $A$, Dependence of gain on background. Collected current responses (mean \pm SEM) from mouse on $\alpha$ ganglion cells in slice $(N=16$; filled circles) and in flat-mount ( $N=13$; open circles) preparations. Smooth fit from Equation 5 : exponent $m=-0.78 \pm 0.05$ for slice, $-0.62 \pm 0.05$ for flat mount (mean \pm SD); $a=0.01$ for slice and 0.19 for flat mount; $b$ fixed at $1.3 ; c=2.91$ for slice and 2.44 for flat mount; and $d$ fixed at 1 . Voltage clamped at $-60 \mathrm{mV}$. $\boldsymbol{B}$, Dependence of flash-independent noise on background. Smooth fit from Equation 5 with $a$ fixed at $10, b$ fixed at $1.6, c=0.003$, $d=0.007$, and $m$ fixed at -1 . C, Dependence of flash-dependent noise on background. Smooth fit from Equation 5 with $a=0.74, b$ fixed at $1.3, c=0.68, d=0.09$, and $m=-0.54$. $D$, Dependence of threshold on background for mouse (black) and primate (gray). Smooth fit to the mouse data from Equation 6 increased with $M=0.76 \pm 0.08$ (mean $\pm S D$ ), $I_{D}=0.29$, and $K=0.02$.

AII amacrine synapse as a key site of adaptation of rod-mediated signals at low background light levels.

\section{Rod or rod bipolar adaptation cannot explain that of ganglion cells}

Figure 6 shows the gain and flash-independent noise of mouse rod outer segment currents. Figure $6, A$ and $B$, shows individual responses to the same strength flash recorded in darkness and in the presence of a background. The thick traces show average responses. This background $\left(1.3 \mathrm{Rh}^{\star} / \mathrm{rod} / \mathrm{s}\right)$ increased the flashindependent noise but produced little or no change in gain. Figure $6, C$ and $D$, collects measurements of gain and flashindependent noise from 17 rods. Gain began to fall at a background near $2 \mathrm{Rh}^{*} / \mathrm{rod} / \mathrm{s}$ and fell inversely with background for intensities between 10 and $300 \mathrm{Rh}^{\star} / \mathrm{rod} / \mathrm{s}$. The measured dependence of gain on background is consistent with previous studies of mammalian rods and expectations from Weber adaptation (Nakatani et al., 1991; Schneeweis and Schnapf, 2000). Gain decreased at a somewhat lower background (half-desensitizing background of $10 \mathrm{Rh}^{\star} / \mathrm{rod} / \mathrm{s}$ ) than observed previously (Nakatani et al., 1991; Schneeweis and Schnapf, 2000), likely attributable to an increased rod sensitivity under the conditions of our experiments (see Materials and Methods).

Flash-independent noise in the rod signals (Fig. 6D) increased at backgrounds below $1 \mathrm{Rh}^{\star} / \mathrm{rod} / \mathrm{s}$ (before the gain began to decrease) and then decreased at higher intensities. The increase in noise at low intensities is expected from quantal fluctuations produced by the background light, whereas the decrease in noise at higher intensities reflects the decrease in gain. Backgrounds near

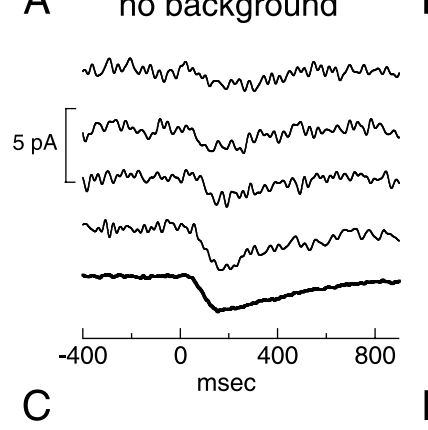

B background
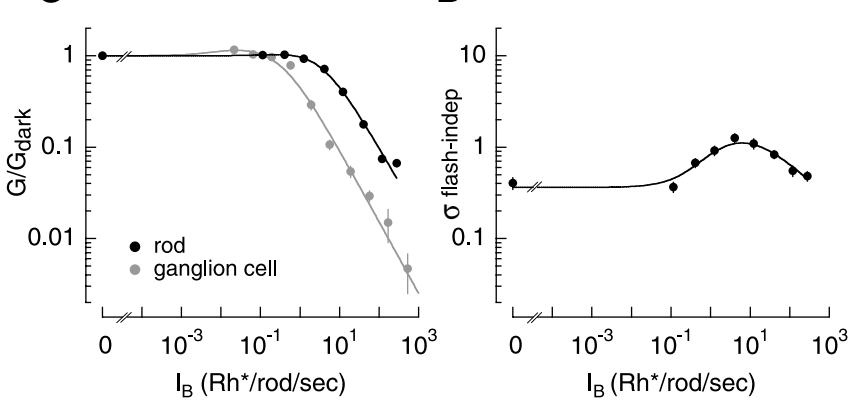

Figure 6. Rod photoreceptor gain and flash-independent noise. $A$, Outer segment current responses of a mouse rod photoreceptor to flashes producing an average of $2.4 \mathrm{Rh} / \mathrm{rod}$ with no background. Flash was delivered at time 0 and was $10 \mathrm{~ms}$ in duration. Template (thick trace) is the average of 40 responses. Noise records were taken from the $400 \mathrm{~ms}$ period before the flash, and response trials were taken from the $400 \mathrm{~ms}$ period after. Filtered at $30 \mathrm{~Hz}$. B, Responses to flashes producing an average of $2.4 \mathrm{Rh} / \mathrm{rod}$ with a background of $0.71 \mathrm{Rh} / \mathrm{rod} / \mathrm{s}$. Template (thick trace) is the average of 40 responses. $C$, Background dependence of gain for 17 mouse rod photoreceptors. Smooth fit from Equation 5 with $m=-0.75 \pm 0.04$ (mean \pm SEM), $a=$ $0.64, b$ fixed at $1.3, c=0.31$, and $d$ fixed at 1 . Superimposed in gray is the gain plot from mouse ganglion cells from Figure $5 A$. Error bars are SEM. $D$, Background dependence of flashindependent noise. Smooth fit from Equation 5 with $a=1.20, b$ fixed at $4, c=0.07, d=0.56$, and $m=-0.39$.

the onset of adaptation in ganglion cells $\left(0.3 \mathrm{Rh}^{\star} / \mathrm{rod} / \mathrm{s}\right)$ produced a $\sim 50 \%$ increase in flash-independent noise.

Figure 7 shows the gain and flash-independent noise of rod bipolar current (i.e., voltage-clamp) and voltage (current-clamp) responses. Figure 7, $A$ and $B$, shows current responses of a mouse rod bipolar to flashes of the same strength delivered in darkness and in the presence of a background. This background (1.4 $\mathrm{Rh}^{\star} /$ $\mathrm{rod} / \mathrm{s}$ ) substantially increased the flash-independent noise but produced little or no change in gain. Figure 7C collects gain measurements for both current $(N=23)$ and voltage $(N=17)$ responses. In both cases, gain increased for backgrounds up to $\sim 10$ $\mathrm{Rh}^{\star} / \mathrm{rod} / \mathrm{s}$ and then decreased. The increase in gain at low background intensities reflects a relief of the thresholding nonlinearity at the rod-to-rod bipolar synapse (Field and Rieke, 2002b; Sampath and Rieke, 2004). The decrease in gain at higher background intensities is at least partially inherited from the decrease in rod gain.

Flash-independent noise of rod bipolar current and voltage responses increased for backgrounds up to $10-20 \mathrm{Rh}^{\star} / \mathrm{rod} / \mathrm{s}$ and then decreased (Fig. 7D), a dependence similar to gain. As for rods, backgrounds near the onset of adaptation in ganglion cells produced a $\sim 50 \%$ increase in the rod bipolar flash-independent noise.

The gain and flash-independent noise of the rod and rod bipolar responses differed from those of the ganglion cells in three ways. First, the gain of the ganglion cell responses decreased at backgrounds $>10$ times less intense than those producing gain decreases in the rods and rod bipolar cells. Second, the gain of the 
A
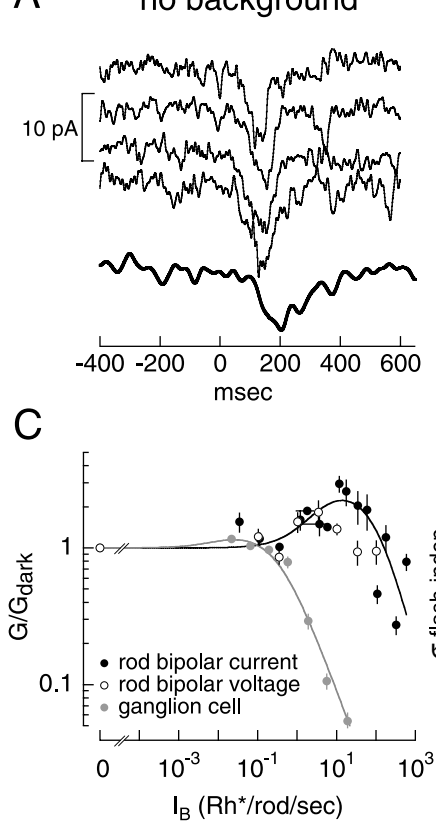

D
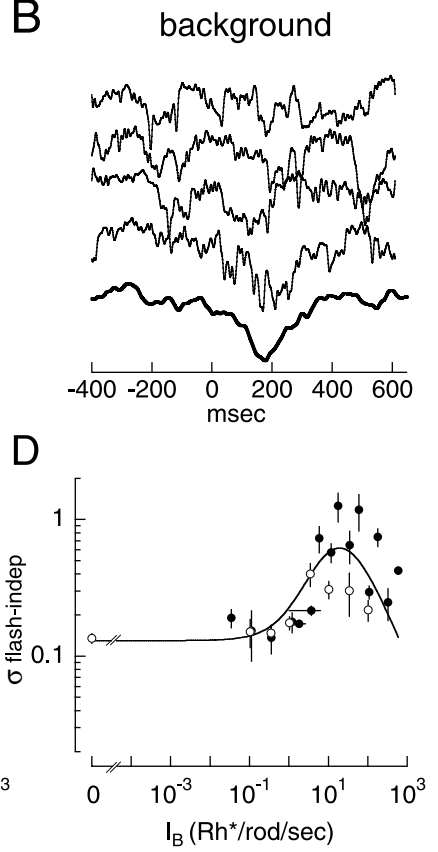

Figure 7. Rod bipolar cell gain and flash-independent noise. $A$, Current responses of a mouse rod bipolar cell to flashes producing an average of $0.1 \mathrm{Rh} / \mathrm{rod}$ with no background. Flash was delivered at time 0 and was $10 \mathrm{~ms}$ in duration. Noise trials were taken from the $300 \mathrm{~ms}$ period before the flash, and response trials were taken from the $300 \mathrm{~ms}$ period after. Template (thick trace) is the average of 20 responses. Holding potential was $-60 \mathrm{mV}$. Filtered at $100 \mathrm{~Hz}$. $\boldsymbol{B}$, Responses to flashes producing an average of $0.1 \mathrm{Rh}^{*} / \mathrm{rod}$ with a background of $1.3 \mathrm{Rh}^{*} / \mathrm{rod} / \mathrm{s}$. Template (thick trace) is the average of 10 responses. $C$, Dependence of rod bipolar gain on background collected from current (filled circles; $N=23$ ) and voltage (open circles; $N=17$ ) responses. Smooth fit from Equation 5 with $m=-1.2 \pm 1.3, a=3.9, b$ fixed at $3, c=0.01$, and $d$ fixed at 1 . Superimposed in gray is the mouse ganglion cell gain. Error bars are SEM. $\boldsymbol{D}$, Dependence of flash-independent noise on background. Smooth fit from Equation 5 with $m$ fixed at -0.7 , $a$ fixed at $16, b$ fixed at $15, c=0.07$, and $d$ fixed at 0.13 .

ganglion cell responses depended less steeply on background than the gain of the rod responses. Third, the flash-independent noise in the ganglion cell responses was relatively insensitive to background light, although that of the rods and rod bipolar cells showed substantial structure. Thus, adaptation in the rod and rod bipolar responses, although significant for backgrounds exceeding $4-5 \mathrm{Rh}^{\star} / \mathrm{rod} / \mathrm{s}$, cannot explain the adaptation observed in the ganglion cell responses.

\section{Gain and noise of AII amacrine responses resemble those of} ganglion cells

AII amacrine cells were the first cells in the rod bipolar pathway to exhibit adaptation comparable with that of the ganglion cells. Figure $8, A$ and $B$, shows current responses of a voltage-clamped AII amacrine cell in darkness and in the presence of a background $\left(1.9 \mathrm{Rh}^{\star} / \mathrm{rod} / \mathrm{s}\right)$. The flash in the presence of the background was eight times brighter than that in darkness, indicating an approximate eightfold decrease in gain. Flash-independent noise also increased in the presence of the background but by less than the gain change.

Figure 8,C and D, shows collected data for 13 voltageclamped AII amacrine cells. Like the ganglion cell gain, the gain of the AII responses showed a small increase for the lowest background intensities probed. Gain began to decline at a background of $0.1 \mathrm{Rh}^{\star} / \mathrm{rod} / \mathrm{s}$ and fell more gradually than expected for Weber adaptation (Fig. 8C). The gain of AII amacrine voltage and current responses scaled nearly identically with background (data not shown). Flash-independent noise depended weakly on back-
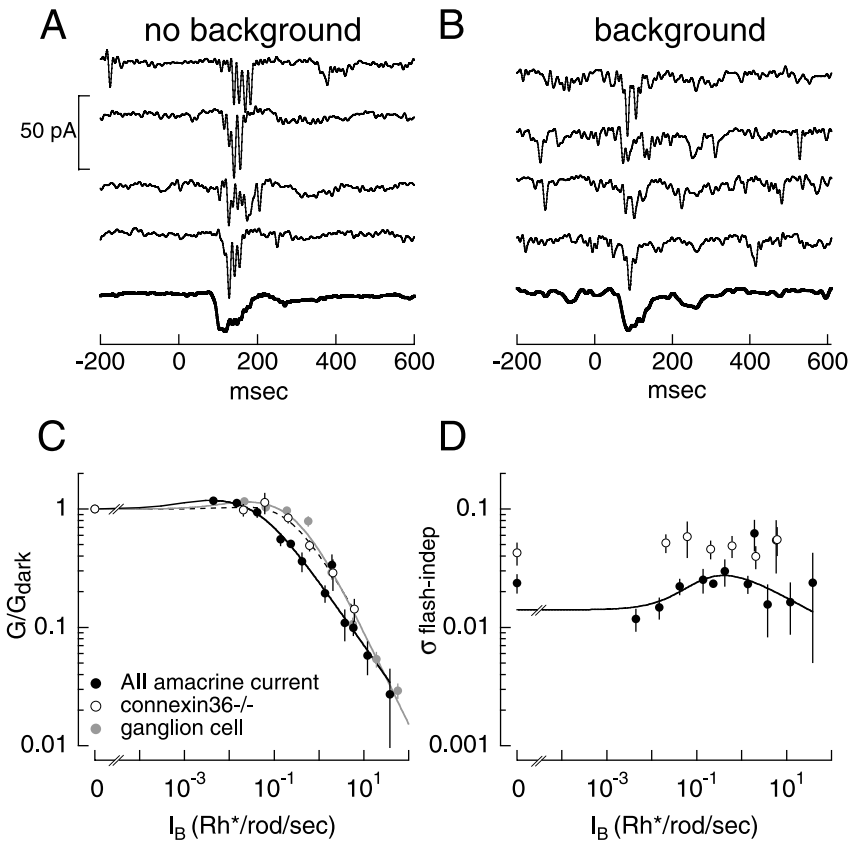

Figure 8. All amacrine cell gain and flash-independent noise. $A$, Current responses of a mouse All amacrine cell to a flash producing an average of $0.16 \mathrm{Rh}^{*} /$ rod with no background. Flash was delivered at time 0 and was 10 ms in duration. Noise trials were taken from the $200 \mathrm{~ms}$ period before the flash, and response trials were from the $200 \mathrm{~ms}$ period after. Template (thick trace) was the average of 28 responses. Holding potential was $-60 \mathrm{mV}$. Filtered at $100 \mathrm{~Hz}$. $\boldsymbol{B}$, Responses to a flash producing an average of $2.6 \mathrm{Rh} / \mathrm{rod}$ with a background of $1.0 \mathrm{Rh} / \mathrm{rod} / \mathrm{s}$. Template (thick trace) was the average of 26 responses. C, Dependence of All amacrine cell gain on background. Black circles plot gain for 13 wild-type All amacrine cells, fit with Equation 5 with exponent $m=-0.54 \pm 0.04$ (mean \pm SD), $a=0.001, b$ fixed at $1.3, c=21.9$, and $d$ fixed at 1 . White circles plot gain for 12 connexin $36^{-/-}$All amacrine cells, fit with Equation 5 with $m=-0.65 \pm 0.15$ (mean \pm SD), $a=0.04, b$ fixed at $1.3, c=4.9$, and $d$ fixed at 1 . Gray circles plot mouse ganglion cell gain. Error bars are SEM. $\boldsymbol{D}$, Dependence of flash-independent noise on background for All amacrine cells from wild-type (filled circles) and connexin $36^{-1-}$ (open circles) mice. Smooth fit from Equation 5 with $m=-0.21, a=0.13, b$ fixed at $3, c=$ 5.8 , and $d=0.01$.

ground: gain changed $>30$-fold between darkness and a background of $40 \mathrm{Rh}^{\star} / \mathrm{rod} / \mathrm{s}$, whereas flash-independent noise changed less than threefold.

Because AII amacrine cells are electrically coupled, the adaptation observed in Figure $8 \mathrm{C}$ could originate from voltagedependent properties of the AII network that were not suppressed by voltage clamp of the recorded cell. To test this possibility, we measured adaptation in AII amacrine cells from mice lacking connexin 36, the connexin forming the gap junctions between AII amacrine cells (Deans et al., 2002). Because of electrical coupling between AII amacrine cells in control mice, the polarity of the light-induced currents did not reverse near 0 $\mathrm{mV}$ as expected for an AMPA receptor-mediated signal. However, light responses of AII amacrine cells from connexin $36^{-/-}$ mice reversed near $0 \mathrm{mV}$ (data not shown), indicating that electrical coupling was effectively disrupted.

The gain of responses of connexin $36^{-/-}$AII amacrine cells (Fig. 8C, open circles) $(N=12)$ had a dependence on background between that of AII amacrine and ganglion cells from control mice: gain began to fall at backgrounds near $0.2 \mathrm{Rh}^{\star} /$ $\mathrm{rod} / \mathrm{s}$ and fell with a slope similar to that of the ganglion cells for backgrounds above $0.5 \mathrm{Rh}^{\star} / \mathrm{rod} / \mathrm{s}$. As in control AII amacrine cells, flash-independent noise changed little with changes in background. The magnitude of the flash-independent noise, however, was higher in connexin36-/- AII amacrine cells. Be- 
cause fewer rods provide input to an AII amacrine in the absence of electrical coupling, both the amplitude and noise of the AII responses should decrease, with a larger effect on the amplitude. Because it is normalized by the response amplitude, the flashindependent noise is expected to increase (Fig. 2 and corresponding text). Because the signal-to-noise ratio is expected to scale as the square root of the number of rod inputs, the approximate twofold increase in noise in the absence of electrical coupling suggests that control AII amacrine cells receive input from approximately four times as many rods as connexin $36^{-/-}$AII amacrine cells. This coupling increases the signal-to-noise ratio of AII amacrine responses, as suggested from modeling work (Vardi and Smith, 1996).

The AII amacrine gain and flash-independent noise resembled those of on $\alpha$ ganglion cells in several ways. First, the backgrounds producing a noticeable gain change in the responses of AII amacrine and ganglion cells were within a factor of 2-3 (gain began to fall at $0.1-0.2 \mathrm{Rh}^{\star} / \mathrm{rod} / \mathrm{s}$ for AII amacrine cells and 0.3 $\mathrm{Rh}^{\star} / \mathrm{rod} / \mathrm{s}$ for ganglion cells). Second, in both cell types, gain declined more gradually than the inverse dependence on background expected for Weber adaptation. Finally, overall changes in flash-independent noise were small compared with changes in gain in both AII amacrine cells and ganglion cells. Thus, the adaptation present in the AII amacrine currents can account for most of the adaptation observed in the ganglion cell responses.

As shown above, gain decreases at low background intensities were absent in the voltage and current responses of rod bipolar cells but present in the current inputs to AII amacrine cells. These gain changes persisted when electrical coupling between AII amacrine cells was disrupted. The presence of gain changes in the AII synaptic inputs and its absence in the rod bipolar voltage responses identify the rod bipolar-to-AII synapse as a key step in adaptation at low light levels.

\section{Noise in the retinal circuitry}

To characterize the efficiency of transmission through the retina, we compared measured noise and threshold with an idealobserver model that predicts the ganglion cell responses from the collection of rods within the ganglion cell receptive field (Fig. $9 A$ ). As described below, this comparison indicates that the retinal circuitry adds substantial noise to the rod signals at low backgrounds.

Rod signals were described by the distribution of responses with and without a flash in the presence of a background light (for details, see Materials and Methods). These signal and noise distributions provided input to a model for how rod signals are integrated by ganglion cells. Efficient readout of the rod signals includes nonlinear processing to separate signals produced by rods that absorb photons from noise produced by rods that do not (Baylor et al., 1984; van Rossum and Smith, 1998). Indeed, the rod-to-rod bipolar synapse implements such a nonlinearity (Field and Rieke, 2002b). Responses from the rod signal and noise distributions were nonlinearly weighted to attenuate noise and small single-photon responses while retaining large singlephoton responses. The properties of the nonlinearity were based on previous work (Field and Rieke, 2002b) (see Materials and Methods). The increase in rod bipolar gain with background shown in Figure $7 C$ could be explained by a single nonlinearity at all backgrounds: although the nonlinearity itself was unchanged, the mean signal produced by the background light decreased its impact (Shiells and Falk, 2002; Sampath and Rieke, 2004).

Nonlinearly weighted rod responses were summed to generate a predicted ganglion cell response. Figure $9 B-D$ shows the pre-
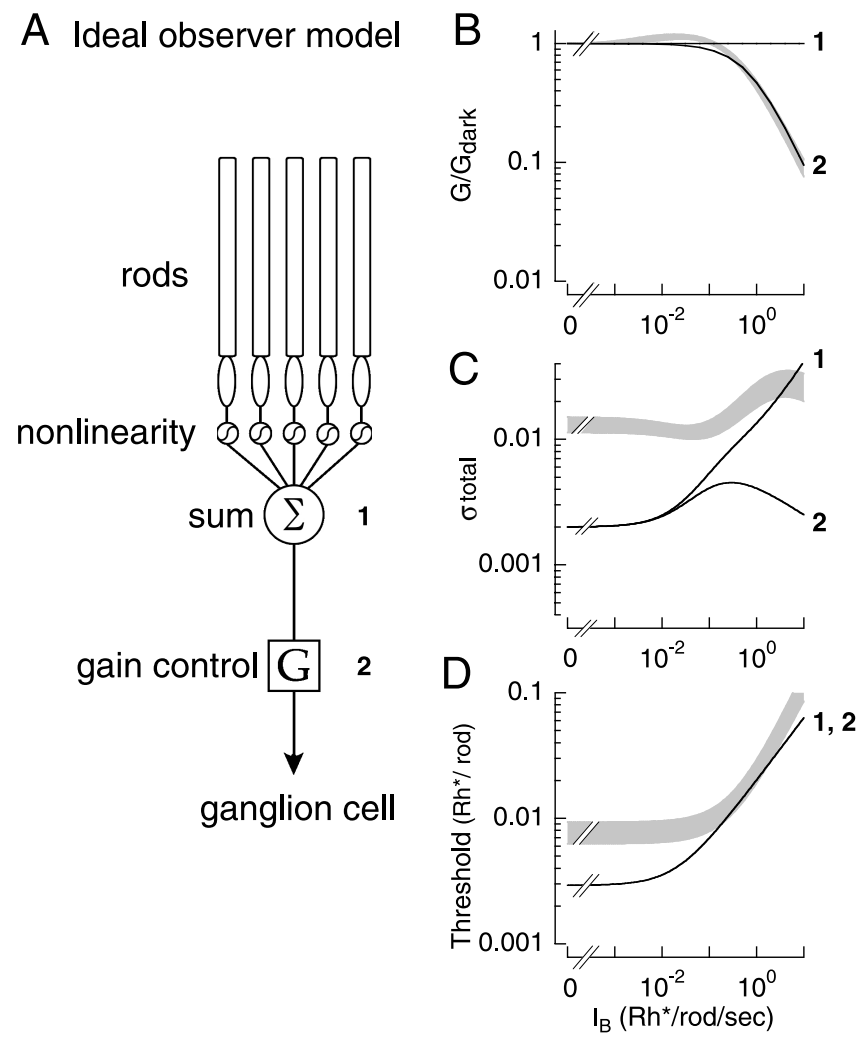

Figure 9. Comparison of experiment with ideal-observer predictions. $A$, Noise and threshold were predicted by passing simulated rod responses through a nonlinearity, summing $N$ signals, and applying a gain change. Location 1 represents the signal before the gain change, and location 2 represents the signal after. The nonlinearity was a cumulative Gaussian (midpoint of 1.3; SD of 0.1). N was 4096 for $\alpha$ ganglion cell predictions. $\boldsymbol{B}$, Response gain before (1) and after (2) the gain control site. Gray region shows fits to upper (measured + SEM) and lower (measured - SEM) limits to the measured gain from Figure 5A. Gain in the model was chosen to match that measured and scaled with background as $\left(0.3+I_{B}\right)^{-0.8}$. C, Total flashindependent and flash-dependent noise at threshold of the model before (1) and after (2) the gain change. Gray region shows fits to upper (measured + SEM) and lower (measured - SEM) limits to the measured total noise from Figure 5, $B$ and $C$. D. Threshold of the ideal-observer model (black) compared with fits to the upper (measured + SEM) and lower (measured SEM) limits to the measured threshold from Figure $5 D$ (gray region).

dicted gain, total noise (Eq. 2), and threshold for an equivalent disc pool of 4096 rods, a lower bound for the effective number of rod inputs to an $\alpha$ ganglion cell in the slice (see Materials and Methods). Flash-independent noise dominated the total noise in the model. Model responses are plotted before (Fig. 9A, location 1) and after (location 2) the gain control; the gain control was chosen to match that measured (Fig. $5 A$ ), i.e., gain was initially independent of background and then fell as $I_{B}{ }^{-0.8}$ (Fig. $9 B$, trace 2 ). The dependence of threshold on background was identical in the two cases (Fig. 9D); this is expected because changes in response gain will not influence threshold unless the gain change is followed by additional noise. Before the gain control, noise was initially constant and then increased as $I_{B}{ }^{0.5}$ because of quantal fluctuations produced by the background light (Fig. $9 C$, trace 1). After the gain, control noise decreased as $I_{B}{ }^{-0.3}$ (Fig. 9C, trace 2).

The measured noise and threshold (Fig. $9 C, D$, gray regions) substantially exceeded those predicted by the ideal-observer model for backgrounds below $0.1 \mathrm{Rh}^{\star} / \mathrm{rod} / \mathrm{s}$, a discrepancy that remained across model parameters consistent with the experiment (see Materials and Methods). For backgrounds above 0.1 $\mathrm{Rh}^{\star} / \mathrm{rod} / \mathrm{s}$, noise from quantal fluctuations could account for experimental threshold. Thus, ganglion cell thresholds did not 
reach the limits to sensitivity set by a noiseless and efficient readout of the rod signals at low backgrounds. Instead, accounting for the measured ganglion cell responses required additional noise in the retinal circuitry.

The conclusion of the modeling, that ganglion cell noise and threshold exceeded those predicted by a noiseless readout of the rod signals, held across a wide range of model parameters (see Materials and Methods). The modeled noise and threshold increased with changes in continuous noise: the $10 \%$ uncertainty in estimated continuous noise produced a $\sim 10 \%$ change in predicted ganglion cell noise and threshold. Predicted noise and threshold differed by $<15 \%$ for locations of the thresholding nonlinearity between 1 and 1.6. Doubling the rate of discrete noise events increased threshold by $<20 \%$. Finally, predicted noise and threshold decreased as the square root of the number of converging rod inputs. Thus, explaining the difference between predicted and measured ganglion cell noise and threshold would require reducing the number of rod inputs to $<500$ from 4096; this is unlikely based on past work (Stone and Pinto, 1992; Sinclair et al., 2004).

Comparing noise in cells throughout the rod bipolar pathway with predictions based on noiseless summation of rod signals identified likely locations of the noise limiting ganglion cell sensitivity. Rod bipolar dark noise was a factor of 2-3 greater than the ideal-observer prediction based on the $\sim 20$ rods that provide input to each rod bipolar cell (Tsukamoto et al., 2001); this suggests that the rod-to-rod bipolar synapse adds considerable noise but not enough to explain ganglion cell noise. AII amacrine dark noise, like that of ganglion cells, exceeded the ideal-observer prediction by a factor of 4-6 for AII amacrine cells in control mice, which receive $\sim 2000$ rod inputs, and in connexin $36^{-/}$mice, which receive $\sim 500$ rod inputs (Sterling et al., 1988). Dark noise in the ganglion cell responses was threefold to sixfold larger than the ideal-observer prediction for pools of 4096-16,384 rods (lower and upper limits to the number of rods providing input to an $\alpha$ ganglion cell; see Materials and Methods).

The similarity of the noise in AII amacrine and ganglion cells, when corrected for differences in rod convergence, can be explained if most of the noise in the ganglion cell responses is inherited from the AII amacrine cells. This does not preclude noise originating between the AII amacrine and ganglion cell but indicates that any such noise is likely to have less of an influence on the detectability of rod-mediated responses than noise inherited from the amacrine responses. For example, quantal noise at the cone bipolar output synapse (Freed, 2000) may minimally obscure the low temporal frequencies that dominate rod-mediated responses because much of the synaptic noise is at higher frequencies. The higher noise level of the AII amacrine responses compared with those of the rod bipolar responses suggests that much of the noise in the ganglion cell synaptic inputs originates at the rod bipolar-to-AII amacrine synapse.

\section{Discussion}

We investigated where the gain of rod-mediated signals is controlled in the retina and the consequences of gain control for sensitivity. Experiments in primate allowed us to relate our results to past work characterizing the effect of dim backgrounds on behavioral sensitivity. Experiments in mouse allowed us to search directly for the site of adaptation in the retinal circuitry. We reached three main conclusions: (1) changes in ganglion cell threshold with background light are accompanied by changes in gain, although noise remains relatively constant; (2) the primary site of gain control is the rod bipolar-to-AII amacrine synapse; and (3) noise in the retinal circuitry, rather than rod noise or noise attributable to quantal fluctuations, limits mouse on $\alpha$ ganglion cell sensitivity at low light levels. Below we relate these results to past physiological and psychophysical work and consider the strategic location of gain controls in a neural circuit.

\section{Comparison with previous physiological measurements}

This work follows a long history of physiological studies of how weak backgrounds affect sensitivity of retinal signals (for review, see Shapley and Enroth-Cugell, 1984; Donner, 1992). Our conclusions are in general agreement with past work, with some notable differences.

Past work indicates that the gain of rod-mediated signals is controlled in rod phototransduction and at one or more sites in the retinal circuitry. The gain of rod outer segment signals is halved for backgrounds that produce 3-20 photoisomerizations in each 300 ms integration time (Tamura et al., 1989; Nakatani et al., 1991) (Fig. 6). These backgrounds are substantially higher than those required to halve the sensitivity of the ERG scotopic threshold response (a signal originating at unknown sites in the inner retina) (Frishman and Sieving 1995; Naarendorp et al., 2001; Saszik et al., 2002) and the sensitivity of spike responses of cat retinal ganglion cells measured in vivo (Barlow and Levick, 1969; Enroth-Cugell and Shapley, 1973). Furthermore, weak backgrounds decrease the gain of the scotopic threshold response but not the ERG b-wave (attributed to activity of rod bipolar cells). In toad, the gain of ganglion cell responses was reduced at lower background intensities than the gain of rod or horizontal cell responses (Copenhagen et al., 1990). Together, these observations indicate that the gain of retinal signals is first controlled in the inner retina. These observations are consistent with our conclusion that the rod bipolar-to-AII amacrine synapse controls the gain of rod-mediated signals at low background intensities.

Our results differ from those of past studies in two respects. First, the background dependence of rod bipolar signal gain differs substantially from the ERG b-wave. This difference indicates either that in vivo and in vitro bipolar responses differ or that the b-wave is not an accurate representation of rod bipolar signaling under all conditions. Possible differences between in vivo and in vitro preparations do not appear to be caused by slicing the retina because the sensitivity of ganglion cells in our slice and flatmount preparations are consistent with each other and with other studies of mouse ganglion cells (see Materials and Methods). Second, in vivo recordings from cat ganglion cells (Barlow and Levick, 1969; Enroth-Cugell and Shapley, 1973) and measurements of the scotopic threshold response (Frishman and Sieving, 1995; Naarendorp et al., 2001; Saszik et al., 2002) show decreases in gain for weaker backgrounds than those required to reduce the gain of the AII amacrine responses. Species differences likely contribute to this difference, because the backgrounds required to reduce the gain of the scotopic threshold response differ by a factor of $\sim 5$ between cat and mouse (Frishman and Sieving, 1995; Saszik et al., 2002). In the most directly comparable studies, ERG recordings in mouse (Saszik et al., 2002), gain decreased at light levels approximately fivefold less than our AII recordings. Several issues could contribute to this remaining difference: (1) calibration issues make comparisons of light levels accurate to at best a factor of $\sim 4$ between in vivo and in vitro preparations; (2) the scotopic threshold response may reflect gain changes not shared by AII amacrine cells and on $\alpha$ ganglion cells; and (3) as discussed above, in vitro preparations may not accurately reflect the in vivo behavior of the retina. 


\section{Comparison with behavioral threshold}

The ability of rod vision to avoid saturation as light levels increase is a classic behavioral result (for review, see Barlow, 1957; Donner, 1992). For weak backgrounds, behavioral threshold increases proportionally to the square root of the background intensity for small, brief flashes $\left(I_{B}{ }^{0.5}\right)$ : the Rose-deVries region (de Vries, 1943; Rose, 1948). Most configurations of the background and test flash, however, produce a steeper dependence in behavioral studies (Barlow, 1957) and in recordings from retinal ganglion cells (Barlow and Levick, 1976; Lennie, 1979). Indeed, thresholds for mouse and primate ganglion cells in the slice depended on background approximately as $I_{B}{ }^{0.7}$. A possible explanation is the recruitment of an inhibitory surround of the ganglion cell receptive field as background increases (Barlow and Levick, 1976).

\section{Limits to retinal sensitivity}

At low backgrounds, noise in the responses of ganglion cells and AII amacrine cells exceeded predictions based on a noiseless and efficient readout of rod signals. This is consistent with the absolute thresholds of dark-adapted primate ganglion cells, which exceed limits set by the rods within their receptive field (Field et al., 2003; Uzzell et al., 2003). Noise in the AII amacrine responses exceeded expectations based on noise in the rod bipolar responses; thus, the limiting noise appears to be generated at the rod bipolar-to-AII amacrine synapse.

\section{Encoding of signal-to-noise rather than flash strength}

The relative background independence of noise in the current responses of AII amacrine and ganglion cells means that a given amplitude response (e.g., $10 \mathrm{pA}$ ) has the same signal-to-noise at different background light levels: the synaptic currents in both cell types encode signal-to-noise, not flash strength. Although we did not measure ganglion cell spike outputs, Donner et al. (1990) concluded that toad ganglion cell spike trains also encode signalto-noise. Encoding of signal-to-noise rather than flash strength makes effective use of the limited dynamic range of ganglion cell spiking (Brenner et al., 2000). It also simplifies the requirements on the retinal circuitry following the AII amacrine cells and the cortical circuitry reading out the ganglion cell responses because the responses are naturally weighted according to fidelity (Brown and Rudd, 1998).

\section{Receptor and network adaptation}

The gain of rod-mediated signals is controlled by mechanisms in the rod photoreceptors (Fig. 6) (Baylor et al., 1980; Nakatani et al., 1991) and in the retinal circuitry (Fig. 8) (Dowling, 1967; Barlow and Levick, 1969; Frishman and Sieving, 1995; Frishman et al., 1996). Why have multiple stages of gain control? The ability of the retina to operate over an enormous range of light levels relies on balancing the amplification required to achieve high sensitivity with the need to avoid saturation. Such balance is achieved by multiple stages of gain control, critically placed to allow the high degree of convergence characteristic of the rod circuitry (Sterling et al., 1988) without overwhelming responses of the cells involved.

Adaptation occurs at light levels at which photons arrive rarely at individual rods, e.g., the onset of adaptation is near $0.1 \mathrm{Rh}^{\star} /$ $\mathrm{rod} / \mathrm{s}$. At these light levels, effective adaptation in the rods would require an integration time of tens or hundreds of seconds. Furthermore, rods are not at risk of saturation until single-photon responses begin to overlap temporally, i.e., at light levels $\sim 30$ times higher than the onset of adaptation. Rushton (1965) argued that adaptation at such low light levels requires that the adapting unit integrate over a region larger than the receptive field of a single rod, i.e., network adaptation. The high degree of convergence of rod inputs to AII amacrine cells $(\sim 500$ rods provide direct input to each AII) and the high gain of the dark-adapted rod bipolar-to-AII synapse make the AII light responses particularly susceptible to saturation. Adaptation at this synapse prevents such saturation.

Like the visual system, the olfactory system must balance the competing needs of amplification to detect weak signals (Menini et al., 1995; Bhandawat et al., 2005) and gain control (Zufall and Leinders-Zufall, 2000) to avoid saturation. However, both anatomical convergence and the importance of receptor and network adaptation differ substantially in the two systems. Most convergence in the olfactory system is at the first stage of processing in which thousands of olfactory receptor neurons synapse onto 5-25 mitral cells in each glomerulus (Firestein, 2001). Thus, the potential problem of saturation is immediate and prevented by adaptation in the olfactory receptor cell (Zufall and LeindersZufall, 2000). Like the background lights required for adaptation in the rod bipolar pathway, the signal controlling adaptation in a single olfactory receptor is itself quite variable, suggesting that gain fluctuations could introduce substantial noise in both systems.

The distributed gain control in the retina allows a later stage of adaptation to dominate when signals are sparse, and saturation presents a problem only for cells receiving many converging inputs. As light levels increase, the visual system relies on receptor adaptation like the olfactory system (for review, see Walraven et al., 1990). In general, sensory systems benefit from convergence when adaptation is postponed until saturation is imminent. Multiple stages of gain control, such as photoreceptor and network, allows the retina to take advantage of convergence while avoiding saturation.

\section{References}

Armstrong-Gold CE, Rieke F (2003) Bandpass filtering at the rod to secondorder cell synapse in salamander (Ambystoma tigrinum) retina. J Neurosci 23:3796-3806.

Barlow HB (1956) Retinal noise and absolute threshold. J Opt Soc Am 46:634-639.

Barlow HB (1957) Increment thresholds at low intensities considered as signal/noise discriminations. J Physiol (Lond) 136:469-488.

Barlow HB (1965) Optic nerve impulses and Weber's law. Cold Spring Harb Symp Quant Biol 30:539-546.

Barlow HB, Levick WR (1969) Three factors limiting the reliable detection of light by retinal ganglion cells of the cat. J Physiol (Lond) 200:1-24.

Barlow HB, Levick WR (1976) Threshold setting by the surround of cat retinal ganglion cells. J Physiol (Lond) 259:737-757.

Barlow HB, Levick WR, Yoon M (1971) Responses to single quanta of light in retinal ganglion cells of the cat. Vision Res [Suppl] 3:87-101.

Baylor DA, Lamb TD, Yau KW (1979a) The membrane current of single rod outer segments. J Physiol (Lond) 288:589-611.

Baylor DA, Lamb TD, Yau KW (1979b) Responses of retinal rods to single photons. J Physiol (Lond) 288:613-634.

Baylor DA, Matthews G, Yau KW (1980) Two components of electrical dark noise in toad retinal rod outer segments. J Physiol (Lond) 309:591-621.

Baylor DA, Nunn BJ, Schnapf JL (1984) The photocurrent, noise and spectral sensitivity of rods of the monkey Macaca fascicularis. J Physiol (Lond) 357:575-607.

Bhandawat V, Reisert J, Yau KW (2005) Elementary response of olfactory receptor neurons to odorants. Science 308:1931-1934.

Bloomfield SA, Dacheux RF (2001) Rod vision: pathways and processing in the mammalian retina. Prog Retin Eye Res 20:351-384.

Brenner N, Bialek W, de Ruyter van Steveninck R (2000) Adaptive rescaling maximizes information transmission. Neuron 26:695-702. 
Brown LG, Rudd ME (1998) Evidence for a noise gain control mechanism in human vision. Vision Res 38:1925-1933.

Burns ME, Mendez A, Chen J, Baylor DA (2002) Dynamics of cyclic GMP synthesis in retinal rods. Neuron 36:81-91.

Copenhagen DR, Hemila S, Reuter T (1990) Signal transmission through the dark-adapted retina of the toad (Bufo marinus). Gain, convergence, and signal/noise. J Gen Physiol 95:717-732.

Dacheux RF, Raviola E (1986) The rod pathway in the rabbit retina: a depolarizing bipolar and amacrine cell. J Neurosci 6:331-345.

de Vries HL (1943) The quantum character of light and its bearing upon threshold of vision, the differential sensitivity and visual acuity of the eye. Physica 7:553-564.

Deans MR, Volgyi B, Goodenough DA, Bloomfield SA, Paul DL (2002) Connexin 36 is essential for transmission of rod-mediated visual signals in the mammalian retina. Neuron 36:703-712.

Donner K (1992) Noise and the absolute thresholds of cone and rod vision. Vision Res 32:853-866.

Donner K, Copenhagen DR, Reuter T (1990) Weber and noise adaptation in the retina of the toad Bufo marinus. J Gen Physiol 95:733-753.

Dowling JE (1967) The site of visual adaptation. Science 155:273-279.

Enroth-Cugell C, Shapley RM (1973) Adaptation and dynamics of cat retinal ganglion cells. J Physiol (Lond) 233:271-309.

Field GD, Rieke F (2002a) Mechanisms regulating variability of the single photon responses of mammalian rod photoreceptors. Neuron 35:733-747.

Field GD, Rieke F (2002b) Nonlinear signal transfer from mouse rods to bipolar cells and implications for visual sensitivity. Neuron 34:773-785.

Field GD, Uzzell VJ, Chichilnisky EJ, Rieke F (2003) Limits to retinal ganglion cell sensitivity imposed by rod noise. Soc Neurosci Abstr 29:698.1.

Firestein S (2001) How the olfactory system makes sense of scents. Nature 413:211-218.

Freed M (2000) Parallel cone bipolar pathways to a ganglion cell use different rates and amplitudes of quantal excitation. J Neurosci 20:3956-3963.

Frishman LJ, Sieving PA (1995) Evidence for two sites of adaptation affecting the dark-adapted ERG of cats and primates. Vision Res 35:435-442.

Frishman LJ, Reddy MG, Robson JG (1996) Effects of background light on the human dark-adapted electroretinogram and psychophysical threshold. J Opt Soc Am A 13:601-612.

Graham N, Hood DC (1992) Quantal noise and decision rules in dynamic models of light adaptation. Vision Res 32:779-787.

Hemila S, Lerber T, Donner K (1998) Noise-equivalent and signalequivalent visual summation of quantal events in space and time. Vis Neurosci 15:731-742.

Lennie P (1979) Scotopic increment thresholds in retinal ganglion cells. Vision Res 19:425-430.

Makino CL, Taylor WR, Baylor DA (1991) Rapid charge movements and photosensitivity of visual pigments in salamander rods and cones. J Physiol (Lond) 442:761-780.

Maple BR, Werblin FS, Wu SM (1994) Miniature excitatory postsynaptic currents in bipolar cells of the tiger salamander retina. Vision Res 34:2357-2362.

Masland RH (2001) The fundamental plan of the retina. Nat Neurosci 4:877-886.

Mastronarde DN (1983a) Correlated firing of cat retinal ganglion cells. I. Spontaneously active inputs to $\mathrm{X}$ - and Y-cells. J Neurophysiol 49:303-324.

Mastronarde DN (1983b) Correlated firing of cat retinal ganglion cells. II. Responses of X-and Y-cells to single quantal events. J Neurophysiol 49:325-349.

Menini A, Picco C, Firestein S (1995) Quantal-like current fluctuations induced by odorants in olfactory receptor cells. Nature 373:435-437.

Naarendorp F, Sato Y, Cajdric A, Hubbard NP (2001) Absolute and relative sensitivity of the scotopic system of rat: electroretinography and behavior. Vis Neurosci 18:641-656.

Nakatani K, Tamura T, Yau KW (1991) Light adaptation in retinal rods of the rabbit and two other nonprimate mammals. J Gen Physiol 97:413-435.

O’Brien BJ, Isayama T, Richardson R, Berson DM (2002) Intrinsic physiological properties of cat retinal ganglion cells. J Physiol (Lond) 538:787-802.

Pang JJ, Gao F, Wu SM (2003) Light-evoked excitatory and inhibitory synaptic inputs to ON and OFF $\alpha$ ganglion cells in the mouse retina. J Neurosci 23:6063-6073.

Rieke F, Baylor DA (1996) Molecular origin of continuous dark noise in rod photoreceptors. Biophys J 71:2553-2572.

Rieke F, Baylor DA (1998) Origin of reproducibility in the responses of retinal rods to single photons. Biophys J 75:1836-1857.

Rose A (1948) The sensitivity performance of the human eye on an absolute scale. J Opt Soc Am 38:196-208.

Rushton WA (1962) Visual adaptation. Actual Neurophysiol (Paris) 43:223-235.

Sampath AP, Rieke F (2004) Selective transmission of single photon responses by saturation at the rod-to-rod bipolar synapse. Neuron 41:431-443.

Saszik SM, Robson JG, Frishman LJ (2002) The scotopic threshold response of the dark-adapted electroretinogram of the mouse. J Physiol (Lond) 543:899-916.

Schneeweis DM, Schnapf JL (2000) Noise and light adaptation in rods of the macaque monkey. Vis Neurosci 17:659-666.

Shapley R, Enroth-Cugell C (1984) Visual adaptation and retinal gain controls, Progress in Retinal Research, Vol 3 (Osborne N, Chader G, eds), pp 263-346. London: Pergamon.

Shiells RA, Falk G (2002) Potentiation of “on” bipolar cells flash responses by dim background light and cGMP in dogfish retinal slices. J Physiol (Lond) 542:211-220.

Sinclair JR, Jacobs AL, Nirenberg S (2004) Selective ablation of a class of amacrine cells alters spatial processing in the retina. J Neurosci 24:1459-1467.

Sterling P, Freed MA, Smith RG (1988) Architecture of rod and cone circuits to the on- $\beta$ ganglion cell. J Neurosci 8:623-642.

Stone C, Pinto LH (1992) Receptive field organization of retinal ganglion cells in the spastic mutant mouse. J Physiol (Lond) 456:125-142.

Strettoi E, Raviola E, Dacheux RF (1992) Synaptic connections of the narrow-field, bistratified rod amacrine cell (AII) in the rabbit retina. J Comp Neurol 325:152-168.

Strettoi E, Dacheux RF, Raviola E (1994) Cone bipolar cells as interneurons in the rod pathway of the rabbit retina. J Comp Neurol 347:139-149.

Tamura T, Nakatani K, Yau KW (1989) Light adaptation in cat retinal rods. Science 245:755-758.

Tsukamoto Y, Morigiwa K, Ueda M, Sterling P (2001) Microcircuits for night vision in mouse retina. J Neurosci 21:8616-8623.

Uzzell VJ, Field GD, Rieke F, Chichilnisky EJ (2003) Detection and temporal sensitivity of primate retinal ganglion cells near absolute threshold. Soc Neurosci Abstr 29:698.2.

van Rossum MC, Smith RG (1998) Noise removal at the rod synapse of mammalian retina. Vis Neurosci 15:809-821.

Vardi N, Smith RG (1996) The AII amacrine network: coupling can increase correlated activity. Vision Res 36:3743-3757.

Viemeister NF, Bacon SP (1988) Intensity discrimination, increment detection, and magnitude estimation for $1-\mathrm{kHz}$ tones. J Acoust Soc Am 84:172-178.

Volgyi B, Deans MR, Paul DL, Bloomfield SA (2004) Convergence and segregation of the multiple rod pathways in mammalian retina. J Neurosci 24:11182-11192.

Walraven J, Enroth-Cugell C, Hood DC, MacLeod DIA, Schnapf JL (1990) The control of visual sensitivity, pp 53-101. San Diego: Academic.

Whitlock GG, Lamb TD (1999) Variability in the time course of single photon responses from toad rods: termination of rhodopsin's activity. Neuron 23:337-351.

Zufall F, Leinders-Zufall T (2000) The cellular and molecular basis of odor adaptation. Chem Senses 25:473-481. 